\section{Add a tax to the EU agricultural policy}

As the debate heats up over the European Union's new Common Agricultural Policy (CAP) for 2020, I propose introducing a progressive tax that is based on farmers' purchase per unit area of pesticides, antibiotics and imported animal feed such as soya beans (see also F. Orsi Nature 541, 464; 2017). Farmers practising sustainable management would be rewarded with increased sales, higher incomes and greater societal respect.

Europe's biodiversity decline is affecting ecosystem services such as pollination and biological pest control (S. G. Potts et al. Nature 540, 220-229; 2016). At present, the costs of pollution and biodiversity loss are not included in consumer prices. Europe's subsidies to farmers have dropped to $40 \%$ of its total budget and need to be cut further because of other financial pressures.

The need for CAP reforms has long been acknowledged, but earlier proposals have been largely unsuccessful (see also Nature 541, 145-146; 2017). Measures already under way include a guaranteed minimum income to farmers and support for new sustainable farming systems.

A progressive tax on agricultural practices that damage health and the environment would soon pay for itself. It would compensate farmers for lower production by reducing costs and increasing market share. Food prices will increase, but will lead to substantial, price-driven shifts in the sale of sustainable products. Frank Berendse Wageningen University, the Netherlands. frank.berendse@wur.nl

\section{Nature-based solutions: criteria}

The lack of a precise definition for the term 'nature-based solutions' risks making it seem arbitrary and impractical (see Nature 541, 133-134; 2017).
We therefore propose three criteria for applying these solutions that will strengthen the concept's role in improving policy on well-defined societal challenges.

First, nature-based solutions need to provide simultaneous benefits for society, the economy and nature. Second, the term should be understood to represent a transdisciplinary umbrella that encompasses experience from existing concepts such as 'blue-green infrastructure' in engineering, 'natural capital' and 'ecosystem services' in economics, and 'landscape functions' in environmental planning. Third, a nature-based solution needs to be introduced gradually, to allow time for careful assessment of its application in real-life settings and further refinement.

Examples of nature-based solutions that respect these three criteria include coastal management to mitigate the effects of climate change, and restoration of floodplains to reduce the risk of downstream flooding. Such initiatives can stimulate cooperation between actors from science, policy and practice.

Christian Albert Leibniz University of Hanover, Germany. Joachim H. Spangenberg Helmholtz Centre for Environmental Research UFZ, Halle, Germany.

Barbara Schröter Leibniz Centre for Agricultural Landscape Research (ZALF), Müncheberg, Germany.

albert@umwelt.uni-hannover.de

\section{Nature-based solutions: sustainable?}

Green practices, such as creating parks in cities for recreation, are being branded as 'nature-based solutions' (see also Nature 541, 133-134; 2017). What we need, however, are sustainable solutions that address human needs effectively over time regardless of whether they are nature-based.

The definition of a naturebased solution is still being debated (see C. Nesshöver et al. Sci. Tot. Environ. 579, 1215-1227; 2017). Intuitively, we may assume that nature always benefits human wellbeing - for instance, through ecosystem 'services'. However, there are ecosystem 'disservices' that work the other way (J. Lyytimäki Ecosyst. Serv. 12, $136 ; 2015)$, allergic reactions to pollen being one example.

The added value of the concept of nature-based solutions is recognizing that these exist and can complement or provide alternatives to human or industrial ones. Thomas Schaubroeck Luxembourg Institute of Science and Technology, Belvaux, Luxembourg. thomas.schaubroeck@list.lu

\section{Nature-based solutions: business}

Europe's ThinkNature project aims to promote 'nature-based solutions' across research, policy, non-governmental organizations and business (see Nature 541, 133-134; 2017). These solutions will guide the design of sustainable cities and territories, realize their economic-development opportunities, and promote business success with beneficial outcomes for society, the environment and human health.

ThinkNature, which is funded by the European Union's research programme Horizon 2020, will transform the market potential for nature-based solutions by using prevailing knowledge and performance data on pioneering practices to identify commercial opportunities and innovation in policy and practice. The project's public online communication platform (www.think-nature.eu, launching at the end of March) will stimulate engagement of multidisciplinary stakeholders. The resultant pool of knowledge and expertise will be applied to implementing solutions, leading to a greater capacity to plan, design and manage these than is currently possible.

The EU is investing in nature-based solutions in a pilot network of 79 cities in 32 countries. ThinkNature will use this network to improve regulatory instruments, share best commercial practices and demonstrate the long-term value of nature-based solutions. Nikolaos P. Nikolaidis, Dionyssia Kolokotsa Technical University of Crete, Chania, Greece. Steven A. Banwart University of Leeds, UK.

nikolaos.nikolaidis@enveng.tuc.gr

\section{Reason travels well through time}

Winston Churchill was one of many renowned thinkers to speculate on extraterrestrial life (see M. Livio Nature 542, 289-291; 2017). Another, the natural scientist Robert Hooke (1635-1703), did so almost 300 years earlier.

Hooke posited that "there may be yet invented several other helps for the eye ... by which we may perhaps be able to discover living Creatures in the Moon or other Planets" (Micrographia, Martyn \& Allestry, 1665).

Livio suggests that today's elected leaders should follow Churchill's example in heeding scientific counsel. In Micrographia, Hooke also warns against misinformation stemming from faulty perception: "The Understanding is to order all the inferior services of the lower Faculties; but yet it is to do this only as a lawful Master, and not as a Tyrant." Reason travels well through time.

Timothy C. Hawes Khon Kaen University, Thailand. timothyhawes@hotmail.com 